\title{
Optimization of the Isolation and Purification Method of Pharmaceutical Grade Pectin from Pomelo Fruit Peels (Citrus maxima Merr. [Family Rutaceae])
}

\author{
Erna C. Arollado, ${ }^{1,2}$ Romeo-Luis F. Ramirez, ${ }^{1}$ Richelle Ann M. Manalo, ${ }^{1}$ \\ Gerwin Louis T. Dela Torre, ${ }^{1}$ Kerstin Mariae G. Ponsaran, ${ }^{1}$ Shaina Mara M. Salvador ${ }^{1}$ and Mae Pauline F. Siocson ${ }^{1}$ \\ ${ }^{1}$ Institute of Pharmaceutical Sciences, National Institutes of Health, University of the Philippines Manila, \\ ${ }^{2}$ Department of Pharmacy, College of Pharmacy, University of the Philippines Manila
}

\begin{abstract}
Background. Pectin is a heteropolysaccharide used in pharmaceutical formulations as a binding agent. Importation of pectin costs billions of Philippine pesos, but the local laboratory-scale production of this excipient from fruit peel wastes is estimated to be cheaper by $80 \%$.

Objective. To address economic and environment concerns associated with pectin production, this study aimed to optimize the isolation and purification of pharmaceutical grade pectin from pomelo (Citrus maxima Merr.) fruit peel as basis for commercial-scale production.

Methods. Pectin was extracted from pomelo using different solvents: $6.2 \% \mathrm{w} / \mathrm{w}$ citric acid, $1 \mathrm{~N}$ acetic acid, $3 \mathrm{~N}$ hydrochloric acid, $3 \mathrm{~N}$ nitric acid, and $3 \mathrm{~N}$ sulfuric acid. Temperatures for extracting pectin were explored at $40^{\circ} \mathrm{C}$, $60^{\circ} \mathrm{C}$, and $90^{\circ} \mathrm{C}$. Obtained pectin samples were characterized based on the following parameters: equivalent weight $(E W)$, methoxyl content (MC), ash content (AC), anhydrouronic acid content (AUA), and degree of esterification (DE).

Results. Highest pectin yield (9.25\%) was obtained using $3 \mathrm{~N}$ nitric acid and $3 \mathrm{~N}$ sulfuric acid at $90^{\circ} \mathrm{C}$. Based from the pharmacopeial standards ( $\mathrm{MC} \geq 6.7$, AUA $\geq 74.0$ ), all the samples did not pass the parameters, except the pectin extracted using $3 \mathrm{~N}$ sulfuric acid at $90^{\circ} \mathrm{C}(\mathrm{MC}=6.76, \mathrm{AUA}=74.61)$.

Conclusion. Among the different solvents used for extraction, $3 \mathrm{~N}$ sulfuric acid produced the highest percent yield of pharmaceutical grade pectin from pomelo fruit peel. Its optimum temperature for extraction was at $90^{\circ} \mathrm{C}$. The sample passed the USP standards of MC values not less than 6.76 and AUA values not less than 74. Under the following conditions, pomelo fruit peel have the potential for commercial-scale production of pharmaceutical grade pectin.
\end{abstract}

Key Words: Citrus maxima, fruit peels, pectin, pharmaceutical grade, pomelo

\section{INTRODUCTION}

Pectin is a heteropolysaccharide used as gelling and binding agent in many pharmaceutical tablet formulations. ${ }^{1}$ The Philippines has been importing this excipient from Denmark, Belgium, Switzerland, and China, with an average annual cost of $\mathrm{PhP} 2.2$ Billion, or around $\mathrm{PhP}$ 27,000 per kilogram. ${ }^{2}$ In other countries, commercial pectin is extracted by treating the raw material with hot dilute mineral acid at $\mathrm{pH} \sim 2 .^{3}$ In an attempt to find cheaper alternative sources

Corresponding author: Erna C. Arollado, RPharm, PhD Institute of Pharmaceutical Sciences

Room 212, National Institutes of Health Building, University of the Philippines Manila 632 Pedro Gil Street, Manila, 1000, Philippines Telephone: Tel. No: +632 5772001 / +63917 8386327 Email: ernaarollado@gmail.com of pectin, its local laboratory-scale production was sourced from mango peels by solubilization at $100^{\circ} \mathrm{C}$ for 60 minutes with acidified water at $\mathrm{pH}$ 2. According to economic analysis, pectin production from mango peels costs $\mathrm{Php}$ 5,667.51 per kilogram, which is cheaper as compared to its importation costs. ${ }^{4}$ 
Aside from mango, pomelo fruit peel is also used as an alternative source of pectin in other countries. ${ }^{5}$ In the Philippines, pomelo production averaged 30 thousand metric tons annually from 2012 to 2014, and its equivalent fruit peel is estimated to be 1,800 tons yearly. ${ }^{6}$ There are no extensive researches yet on the pectin production from fruit peels of pomelo. When these waste materials are recycled and upcycled for commercial scale, it can provide low-cost materials, improve the Philippine economy, and at the same time address environmental concerns.

To fill the knowledge gaps in obtaining pharmaceutical grade pectin from pomelo fruit peels as an alternative pectin source in the country, this study aimed to optimize the isolation and purification methods by varying factors for extraction such as temperature, and type of solvent used, with its corresponding $\mathrm{pH}$.

\section{MATERIALS AND METHODS}

\section{Collection of fruit peel wastes}

The fruit peel of pomelo (Citrus maxima L.) were obtained from Divisoria Market, Manila. The peels were washed with running water and subjected to blanching treatment, resulting to enzymatic inactivation. This was done by immersing the peels in water at $97^{\circ} \mathrm{C}$ for 3 minutes, then transferring to another water bath at room temperature for 15 minutes. $^{7}$ Subsequently, the peels were dried in an aircirculated oven at $50^{\circ} \mathrm{C}$ until a constant weight was obtained. The dried peels were then milled and passed through sieve mesh 60. The resulting fruit peel flour was stored in a polyethylene bag at $4{ }^{\circ} \mathrm{C}$ until used for analysis. ${ }^{8}$

\section{Optimization of pectin extraction and purification}

The optimization of pectin extraction was carried out by preparing 15 flasks, which contained five grams each of the fruit peel flour that was then dissolved in $90 \mathrm{~mL}$ of distilled water. As shown in Table 1, varying volumes of weak and strong acids were respectively added to the flasks, then subjected to
Table 1. Acids added to the flasks and their corresponding temperature for extraction

\begin{tabular}{ccc} 
Flask No. & $\begin{array}{c}\text { Volume and type } \\
\text { of acid added }\end{array}$ & $\begin{array}{c}\text { Temperature } \\
\text { for extraction }\end{array}$ \\
\hline 1 & $10 \mathrm{~mL}, 6.2 \%$ (w/w) citric acid & $40^{\circ} \mathrm{C}$ \\
2 & $10 \mathrm{~mL}, 6.2 \%$ (w/w) citric acid & $60^{\circ} \mathrm{C}$ \\
3 & $10 \mathrm{~mL}, 6.2 \%$ (w/w) citric acid & $90^{\circ} \mathrm{C}$ \\
4 & $10 \mathrm{~mL}, 1 \mathrm{~N}$ acetic acid & $40^{\circ} \mathrm{C}$ \\
5 & $10 \mathrm{~mL}, 1 \mathrm{~N}$ acetic acid & $60^{\circ} \mathrm{C}$ \\
6 & $10 \mathrm{~mL}, 1 \mathrm{~N}$ acetic acid & $90^{\circ} \mathrm{C}$ \\
7 & $6 \mathrm{~mL}, 3 \mathrm{~N}$ hydrochloric acid & $40^{\circ} \mathrm{C}$ \\
8 & $6 \mathrm{~mL}, 3 \mathrm{~N}$ hydrochloric acid & $60^{\circ} \mathrm{C}$ \\
9 & $6 \mathrm{~mL}, 3 \mathrm{~N}$ hydrochloric acid & $90^{\circ} \mathrm{C}$ \\
10 & $6 \mathrm{~mL}, 3 \mathrm{~N}$ nitric acid & $40^{\circ} \mathrm{C}$ \\
11 & $6 \mathrm{~mL}, 3 \mathrm{~N}$ nitric acid & $60^{\circ} \mathrm{C}$ \\
12 & $6 \mathrm{~mL}, 3 \mathrm{~N}$ nitric acid & $90^{\circ} \mathrm{C}$ \\
13 & $6 \mathrm{~mL}, 3 \mathrm{~N}$ sulfuric acid & $40^{\circ} \mathrm{C}$ \\
14 & $6 \mathrm{~mL}, 3 \mathrm{~N}$ sulfuric acid & $60^{\circ} \mathrm{C}$ \\
15 & $6 \mathrm{~mL}, 3 \mathrm{~N}$ sulfuric acid & $90^{\circ} \mathrm{C}$ \\
\hline
\end{tabular}

varying temperatures for 1 hour with continuous stirring. The resulting $\mathrm{pH}$ values ranged from 1.2-4.2. The hot acid extract was filtered using Buchner funnel through Whatman No. 1 filter paper. The digestion was repeated for another 30 minutes. The filtrate from the first and second digestion were combined and placed overnight in a refrigerator at $4{ }^{\circ} \mathrm{C}$ after which, pectin was precipitated by adding $95 \%$ ethanol to the cooled filtrate, and the mixture was left undisturbed for 30 minutes. The mixture was filtered and then soaked overnight in $95 \%$ ethanol. The isolated pectin was washed with $5 \mathrm{~mL}$ portions of acetone to remove any remaining impurities. The purified pectin was oven dried at $35-40^{\circ} \mathrm{C}$ and the percentage yield was computed. The dried pectin isolate was ground to obtain powdered pectin.

\section{Characterization of pectin 9}

As summarized in Table 2, the parameters used to characterize extracted and purified pectin were equivalent weight (EW), methoxyl content (MC), ash content determination (AC), anhydrouronic acid content (AUA),

Table 2. Acids added to the flasks and their corresponding temperature for extraction

\begin{tabular}{|c|c|c|}
\hline Parameters & Chemicals/Variables used & Formula \\
\hline EW & $\begin{array}{l}95 \% \text { ethanol, } \mathrm{NaCl} \\
\mathrm{CO}_{2} \text {-free distilled water, } \\
\text { phenol red, } 0.1 \mathrm{~N} \mathrm{NaOH}\end{array}$ & Equivalent weight $=\frac{\text { wt. of sample }(\mathrm{g}) \times 1000}{\text { vol. of alkali }(\mathrm{mL}) \times \text { Normality of alkali }}$ \\
\hline MC & $\begin{array}{l}0.25 \mathrm{~N} \mathrm{NaOH}, 0.25 \mathrm{~N} \\
\mathrm{HCl}, 0.1 \mathrm{~N} \mathrm{NaOH} \\
\text { phenolphthalein }\end{array}$ & Methoxyl content $(\%)=\frac{\text { vol. of alkali }(\mathrm{mL}) \times \text { Normality of alkali } \times 31 \times 100}{\text { wt. of sample }(\mathrm{g}) \times 1000}$ \\
\hline$A C$ & $\begin{array}{l}0.1 \mathrm{~N} \mathrm{HCl}, 0.1 \mathrm{~N} \mathrm{NaOH} \text {, } \\
\text { phenolphthalein }\end{array}$ & Alkalinity $(\%)=\frac{(\text { Blank }- \text { Titre }) \times \text { Normality of alkali } \times 60 \times 100}{\text { wt. of ash }(\mathrm{g}) \times 1000}$ \\
\hline AUA & $\begin{array}{l}\text { alkali milli-equivalents of } \\
\text { EW, MC, \& AC }\end{array}$ & AUA $(\%)=\frac{176(\text { m.e. for free acid }+ \text { m.e. for saponification }+ \text { m.e. for titratable ash }) \times 100}{\text { wt. of sample }(g) \times 1000}$ \\
\hline $\mathrm{DE}$ & $M C$ and $A U A$ values & Degree of esterification $=\frac{176 \times \text { methoxyl content }(\%) \times 100}{31 \times \text { anhydrouronic acid }(\%)}$ \\
\hline
\end{tabular}

${ }^{*}$ Procedures were lifted from the study of Kanmani P, Dhivya E, Aravind J, Kumaresan K (2014). EW = Equivalent Weight, MC = Methoxyl Content, $A C=$ Ash Content Determination, $A \cup A=$ Anhydrouronic Acid Content, $D E=$ Degree of Esterification . 
and degree of esterification (DE). The working standard used for comparison was apple pomace pectin. The purity of the samples was primarily based on MC and AUA content.

\section{Statistical analysis}

The data were analyzed using Microsoft Excel 2016 Analysis ToolPak. The 2-way ANOVA was used for the analysis of percent yield in response to the variation of solvent type used and temperature applied. The t-test was used to compare other parameters against the standard.

\section{RESULTS AND DISCUSSION}

All measurements were done in triplicates for each of the sample. The characterization of the pectin extracted from pomelo fruit peel under various conditions is summarized in Table 3. Among the samples, $3 \mathrm{~N}$ nitric acid and $3 \mathrm{~N}$ sulfuric acid at $90^{\circ} \mathrm{C}$ gave the highest pectin yield at $9.25 \%$. The different solvent type $(\mathrm{p}=0.015)$ and temperature applied $(\mathrm{p}=0.006)$ were found to be statistically significant in optimizing pectin isolation in terms of percent yield as seen on Table 3. Samples with less than $1 \%$ yield were not sufficient to conduct the AC, AUA, and DE determination. Apple pomace was used as standard due to its high amount of pectic substances. ${ }^{10}$

The EW of pectin samples indicates its jelly-forming ability, wherein better gelling agents possess higher equivalent weight. Among the samples with greater than $1 \%$ yield, pectin extracted using $3 \mathrm{~N}$ hydrochloric acid at $90^{\circ} \mathrm{C}$ had the greatest gelling property $(\mathrm{EW}=984.13)$, followed by $3 \mathrm{~N}$ sulfuric acid at $60^{\circ} \mathrm{C}(\mathrm{EW}=968.25)$. This may be attributed to the strong acid properties of the two solvents responsible for dissolving pectin substances with their respective optimum temperatures for extraction. ${ }^{11}$ Using t-test to compare against the standard $(\mathrm{EW}=1174.84)$, the samples were statistically significant $(\mathrm{p}<0.05)$ in terms of difference in gelling properties.

As per pharmacopeial standards, pectin yields should not have methoxy groups $\left(-\mathrm{OCH}_{3}\right)$ less than $6.7 \%$ while the anhydrouronic acid $\left(\mathrm{C}_{6} \mathrm{H}_{10} \mathrm{O}_{7}\right)$ content, should not be less than $74.0 \%$ of the dried material. ${ }^{12}$ The $\mathrm{MC}$ is an important factor in controlling the setting time and gel formation of pectin due to methoxy groups present, while AUA content determines the galacturonic acid content that indicates the purity of pectin since galacturonic acid units constitute the pectin backbone..$^{13}$ Among the samples subjected to different extraction solvents at various temperatures, both the standard and pectin extracted using $3 \mathrm{~N}$ sulfuric acid at $90^{\circ} \mathrm{C}$ passed the USP criteria. The t-test suggests that the sample is statistically different from the standard $(\mathrm{p}<0.05)$. DE values on the other hand indicated the rate of gel formation, ${ }^{14}$ the pectin samples had $\mathrm{DE}$ values $<72 \%$, therefore classified as slow set.

\section{CONCLUSION}

To optimize the isolation and purification of pharmaceutical grade pectin from pomelo peel, different solvents were tested at varying temperatures. It was found that the extraction of pectin obtained the highest yield (9.25\%) using $3 \mathrm{~N}$ nitric acid and $3 \mathrm{~N}$ sulfuric acid at $90^{\circ} \mathrm{C}$. Based from the USP criteria for pectin characterization $(\mathrm{MC} \geq 6.7, A U A$ $\geq 74.0$ ), only pectin extracted at $90^{\circ} \mathrm{C}$ using $3 \mathrm{~N}$ sulfuric acid $(\mathrm{MC}=6.76, \mathrm{AUA}=74.61)$ passed the parameters. Other

Table 3. Characteristics of pectin extracted from pomelo fruit peel under different conditions

\begin{tabular}{|c|c|c|c|c|c|c|}
\hline Acid, Temperature & $\% Y$ & EW & MC & $\mathrm{AC}$ & AUA & DE \\
\hline \multicolumn{7}{|l|}{$6.2 \%(w / w)$ Citric acid } \\
\hline $40^{\circ} \mathrm{C}$ & 0.19 & 1000 & 1.55 & $* *$ & $* *$ & $* *$ \\
\hline $60^{\circ} \mathrm{C}$ & 0.79 & 1000 & 1.55 & $* *$ & $* *$ & $* *$ \\
\hline $90^{\circ} \mathrm{C}$ & 3.18 & 606.06 & 4.34 & 49.14 & 54.03 & 45.6 \\
\hline \multicolumn{7}{|l|}{ 1N Acetic acid } \\
\hline $40^{\circ} \mathrm{C}$ & 0.29 & 2000 & 1.55 & $* *$ & $* *$ & $* *$ \\
\hline $60^{\circ} \mathrm{C}$ & 0.33 & 2000 & 1.55 & $* *$ & $* *$ & $* *$ \\
\hline $90^{\circ} \mathrm{C}$ & 0.55 & 2000 & 1.55 & $* *$ & $* *$ & $* *$ \\
\hline \multicolumn{7}{|l|}{ 3N Hydrochloric acid } \\
\hline $40^{\circ} \mathrm{C}$ & 0.33 & 888.89 & 2.07 & $* *$ & $* *$ & $* *$ \\
\hline $60^{\circ} \mathrm{C}$ & 3.04 & 882.74 & 2.95 & 48.9 & 39.83 & 41.97 \\
\hline $90^{\circ} \mathrm{C}$ & 5.27 & 984.13 & 3.46 & 49.48 & 5.27 & 39.69 \\
\hline \multicolumn{7}{|l|}{ 3N Nitric acid } \\
\hline $40^{\circ} \mathrm{C}$ & 0.79 & 761.17 & 3.15 & $* *$ & $* *$ & $* *$ \\
\hline $60^{\circ} \mathrm{C}$ & 3.06 & 674.33 & 1.96 & 47.46 & 38.31 & 29.1 \\
\hline $90^{\circ} \mathrm{C}$ & 9.25 & 888.78 & 6.18 & 3.16 & 62.15 & 56.48 \\
\hline \multicolumn{7}{|l|}{$3 \mathrm{~N}$ Sulfuric acid } \\
\hline $40^{\circ} \mathrm{C}$ & 3.35 & 811.97 & 3.72 & 45.06 & 50.92 & 41.47 \\
\hline $60^{\circ} \mathrm{C}$ & 5.93 & 968.25 & 4.24 & 11.34 & 42.59 & 56.47 \\
\hline $90^{\circ} \mathrm{C}$ & 9.25 & 844.38 & 6.76 & 7.8 & 74.61 & 51.47 \\
\hline Apple pomace (Std) & $\mathrm{N} / \mathrm{A}$ & 1174.84 & 10.31 & 2.16 & 79.01 & 74.07 \\
\hline USP Acceptance Criteria & $\mathrm{N} / \mathrm{A}$ & N/A & $\geq 6.7$ & $\mathrm{~N} / \mathrm{A}$ & $\geq 74.0$ & $\mathrm{~N} / \mathrm{A}$ \\
\hline
\end{tabular}


parameters for pectin characterization suggested its good gelling quality. Under the conditions using the optimized method of pectin extraction, pomelo fruit peel could be a potential source of pharmaceutical grade pectin.

\section{Acknowledgments}

The authors would like to express their deepest gratitude to the Department of Industrial Pharmacy, College of Pharmacy, University of the Philippines Manila for lending us their facilities, and the National Institutes of Health for funding this project.

\section{Statement of Authorship}

All authors approved the final version submitted.

\section{Author Disclosure}

All authors declared no conflict of interest.

\section{Funding Source}

This paper was funded by the National Institutes of Health - Institute of Pharmaceutical Sciences.

\section{REFERENCES}

1. Wen H, Park K. Oral controlled release formulation design and drug delivery. Singapore: John Wiley \& Sons, Inc; 2010. p. 77.

2. Department of Science and Technology - Philippine Council for Agriculture, Aquatic and Natural Resources Research and Development, Pectin extraction process headed for commercialization [Online]. 2011 [cited 2017 April]. Available from: http://www.pcaarrd. dost.gov.ph/home/portal/index.php/quick-information-dispatch/ 2198-pectin-extraction-process-headed-for-commercialization.

3. May CD. Industrial pectins: sources, production and applications. Carbohydrate Polymers.1990;12(1):79-99. https://doi.org/10.1016/ 0144-8617(90)90105-2.
4. Gragasin CB, Ligisan AR, Torres RC, Estrella R. Utilization of mango peels as source of pectin [Online]. 2014 [cited 2017 April]. Available from: http://www.philmech.gov.ph/upload/PUBLICATIONS/tech_ bulletin/2014/Technical\%20Bulletin\%207.pdf. DOI: 10.4172/21577110.S1.002.

5. Quoc LPT, Huyen VTN, Hue LTN, et al. Extraction of pectin from pomelo (Citrus maxima) peels with the assistance of microwave and tartaric acid. International Food Research Journal. 2015;22(4):1637-41.

6. Philippine Statistics Authority. Supply utilization accounts (SUA) of selected agricultural commodities 2012-2014 [Online]. 2015 [cited 2017 April]. Available from: https://psa.gov.ph/sites/default/files/ sua_12-14.pdf.

7. Reis FR. New perspectives on food blanching. Brazil: Springer International Publishing; 2016. p. 8.

8. Pinheiro ER, Silva IM, Gonzaga LV, et al. Optimization of extraction of high-ester pectin from passion fruit peel (Passiflora edulis flavicarpa) with citric acid by using response surface methodology. Bioresource Technol. 2008;99(13):5561-6. DOI: 10.1016/j.biortech.2007.10.058.

9. Kanmani P, Dhivya E, Aravind J, Kumaresan K. Extraction and analysis of pectin from citrus peels: augmenting the yield from Citrus limon using statistical experimental design. Iranica Journal of Energy \& Environment. 2014;5(3):303-12.

10. Canteri-Schemin MH, Fertonani HC, Waszczynskyj N, Wosiacki G. Extraction of pectin from apple pomace. Braz. arch. biol. technol. 2005;48(2):259-66. http://dx.doi.org/10.1590/S151689132005000200013.

11. Sayah MY, Chabir R, Nadia EM, et. al. Comparative study on pectin yield according to the state of the orange peels and acids used. International Journal of Innovative Research in Science, Engineering and Technology. 2014;3(8):15658-65.

12. U.S. Pharmacopoeia-National Formulary [USP 39, NF 34]. Pectin. Rockville, Md.: United States Pharmacopeial Convention, Inc.;2016. p. 5290.

13. Devi WE, Shukla RN, Abraham A, Jarpula S, Kaushik U. Optimized extraction condition and characterization of pectin from orange peel. International Journal of Research in Engineering \& Advanced Technology. 2014;2(2):1-9.

14. Shaha RK, Nayagi Y, Punichelvana A, Afandi A.Optimized extraction condition and characterization of pectin from kaffir lime (Citrus hystrix). Malaysia Research Journal of Agriculture and Forestry Sciences. 2013;1(2):1-11. 